\title{
A LEGALIDADE DA PRODUÇÃO DE PROVAS DOS PROCESSOS ADMINISTRATIVOS DE ALCOOLEMIA NO TRÂNSITO
}

\author{
Thayane Maio Benevides dos Santos* \\ Antonio José Vieira Junior**
}

\section{RESUMO}

O presente artigo científico analisa a legalidade dos meios de provas do processo administrativo de alcoolemia, abrangendo a definição e a evolução histórica do trânsito no Brasil, além das alterações sofridas no Código de Trânsito Brasileiro com a Lei $\mathrm{n}^{\circ} 11.275 / 06$, Lei $\mathrm{n}^{\circ} 11.705 / 08$, Lei $\mathrm{n}^{\circ} 12.760 / 12$ e a Lei $\mathrm{n}^{\circ} 13.281 / 16$. Referidas legislações serão estudadas concomitantemente com a Resolução $n^{\circ} 432 / 13$ do CONTRAN que dispõe sobre os procedimentos a serem adotados pelas autoridades de trânsito e seus agentes na fiscalização, através do teste do etilômetro, na verificação dos sinais de alteração da capacidade psicomotora e recusa aos exames. O trabalho também é embasado na Constituição Federal, nos direitos e garantias fundamentais, além da supremacia do interesse público em garantir a segurança no trânsito. Busca esclarecer entendimentos divergentes sobre a recusa ao teste do etilômetro que foram sanados com o advento da lei $\mathrm{n}^{\circ} 13.281 / 16$ que

\footnotetext{
* SANTOS. Thayane Maio Benevides dos Santos. Graduada em Direito Universidade Metodista de São Paulo. E-mail: thay.mbs@hotmail.com ** Professor orientador: VIEIRA JUNIOR. Antonio José. Advogado. Mestre em Direitos Difusos e Coletivos pela Universidade Metropolitana de Santos UNIMES. Especialista em Política Internacional pela Escola de Sociologia e Política de São Paulo.
} 
incluiu o artigo 165-A no capítulo "das infrações" no Código de Trânsito Brasileiro. Pretende-se demonstrar que todos os procedimentos realizados na fiscalização e após, estão em conformidade com a lei. O estudo constatou que infelizmente ainda há um índice grande de condutores que dirigem após ingerir bebida alcoólica. Nossas leis são brandas comparadas aos outros países e ineficazes diante do desrespeito dos motoristas, que ao infringi-las ocasionam um número elevado de acidentes com vítimas envolvendo direção e álcool.

Palavras-chave: Legalidade. Meios de prova. Trânsito. Alcoolemia. Processo administrativo

\section{THE LEGITIMACY OF THE MEANS OF PROOF IN THE DRIVE UNDER INFLUENCE OF ALCOHOL ADMINISTRA- TIVE PROCESS}

\section{ABSTRACT}

This academic paper analyzes the legitimacy of the means of proof in the drive under influence of alcohol administrative process. It covers its definition, the Brazilian traffic history and the alterations made on the Brazilian Transit Code because of the Law 11.275/06, the Law $11.705 / 08$, the Law $12.760 / 12$ and the Law 13.281/16. Those legislations were analyzed concomitant with the CONTRAN's resolution 432/13, which covers the administrative procedures of drive under influence of alcohol through the "breathalyzer" test, the alteration in the psychomotor capacity and the refusal of providing a specimen for exams. This paper is also based on the Federal Constitution, on the fundamental rights and guarantees and on the government supremacy in ensuring the traffic safety. The chapters will approach the relationship between the alcohol and driving and its implications. This paper clarifies divergent understandings about the refusal of the "breathalyzer" test, which is now covered on the Law 13.281/16 on the article 165-A of the chapter "Infractions" on the Brazilian Transit Code. This paper intends to show that all the procedures accomplished before and after the inspection are in accor- 
dance with the Law. However, this paper has found that there is still a great number of people who drive under the influence of alcohol. Brazilian's law is still soft and ineffective when compared to another countries and the drivers who still refuse to infringe that law are causing a high number of victims.

Keywords: Legitimacy. Administrative process. Drive under influence. Transit.

\section{INTRODUÇÃO}

A evolução e o desenvolvimento da sociedade nos séculos XX e XXI, a necessidade de adequação das pessoas à vida moderna e a franca expansão dos meios de transporte no cotidiano das populações urbanas, colocaram os veículos automotores em posição central no mundo contemporâneo, com alto grau de dependência das pessoas e expressivo incremento do tráfego viário.

Paralelamente, sob a perspectiva sociocultural, houve profundas mudanças culturais na sociedade. Dentre estas, a ampliação do acesso e o aumento do uso de drogas lícitas, socialmente aceitas, fizeram com que transbordassem os limites individuais e passassem a ter relevância cultural e social.

No entanto, há um grave problema quando esses dois mundos se cruzam, isto é, quando os indivíduos fazem uso de drogas (ainda que social e legalmente permitidas) associadas à direção veicular. O resultado, amplamente conhecido e divulgado é o aumento significativo no índice de acidentes de trânsito.

Diante desse quadro, com o aumento acelerado de acidentes e mortes no trânsito, a sociedade civil demanda do legislador a produção de normas cada vez mais eficazes. Não por outra razão, o Código de Trânsito Brasileiro - CTB vem sofrendo diversas alterações, ao longo dos últimos anos, para punir com mais rigor os motoristas infratores e minimizar os acidentes automobilísticos. Dentre estas alterações, as relacionadas aos condutores que dirigem alcoolizados - sem 
dúvidas, as maiores causas de acidentes no trânsito - têm merecido atenção especial, com a instituição de penalidades mais severas aos infratores. Ressalta-se que essas mudanças ocasionam inúmeras divergências doutrinárias e controvérsias, aumentando a relevância do tema também do ponto de vista teórico.

A primeira alteração de impacto ocorreu com a Lei $\mathrm{n}^{\circ}$ $11.275 / 06$, porém destaca-se a Lei $\mathrm{n}^{\circ} 11.705 / 08$, popularmente conhecida por "Lei seca", que trouxe uma nova realidade para o trânsito brasileiro e uma grande repercussão na sociedade. Posteriormente, publicou-se a Lei $n^{\circ} 12.760 / 12$, que passou a prever diversos meios de provas para a penalidade administrativa em questão. E, por fim, a novel alteração, a Lei $n^{\circ} 13.281$, de 4 de maio de 2016, vigorando após 180 dias de sua publicação, que trouxe uma mudança significativa para esse trabalho, transformando uma medida administrativa em conduta infracional disposta no capitulo específico das infrações.

Assim, com o advento da Lei $n^{\circ} 13.281$, a infração consubstanciada na recusa de realização do teste do etilômetro foi formalmente inserida no capítulo "Das infrações" do Código de Trânsito Brasileiro - CTB, com a criação do artigo 165-A. Este novo dispositivo tipifica expressamente a conduta infracional, bem como sua penalidade e as respectivas sanções administrativas, conferindo maior segurança na caracterização da infração e na aplicação da penalidade, que antes figuravam no capítulo "Das Medidas Administrativas".

Pretende-se, pois, discutir neste trabalho um tema de grande repercussão social, na medida em que mesmo aqueles que não dirigem alcoolizados estão sujeitos e expostos a riscos causados por esses indivíduos que atuam com negligência e imprudência ao volante. Ou seja, toda a coletividade é afetada quando alguns condutores decidem dirigir sob o efeito do álcool, inclusive com risco direto à vida de terceiros. 
O objetivo do trabalho é, então, verificar a legalidade dos meios de provas no processo administrativo de alcoolemia, analisando os direitos fundamentais em sopesamento com o interesse público no sentido de assegurar um trânsito viário seguro, avaliando a aparente colisão entre a liberdade individual e o poder-dever do Estado de assegurar segurança e o bem estar de todos.

Serão verificados os diferentes tipos de meios de provas para constatar o teor alcoólico e o uso de substâncias psicoativas, bem como a legalidade de não realizar procedimentos no ato da autuação e ser penalizado com medidas administrativas de mesmo peso.

Como parâmetros, serão consideradas a Constituição Federal de 1988, as alterações sofridas pelo Código de Trânsito Brasileiro e a resolução do Conselho Nacional de Trânsito CONTRAN, que prevê procedimentos específicos para a fiscalização do consumo de álcool (Resolução CONTRAN n432/13), além de doutrinas, jurisprudências e coleta de dados.

\section{DESENVOLVIMENTO}

A Constituição Federal de 1988, em seu artigo 22, inciso XI, conferiu à União a competência privativa para legislar sobre o trânsito e transportes no Brasil, admitindo única e exclusivamente uma legislação de trânsito válida para todo o país.

O conceito de trânsito está mencionado no artigo $1^{\circ}, \S$ $1^{\circ}$ do Código de Trânsito Brasileiro (BRASIL. Lei n ${ }^{\circ}$ 9.503, 1997), "Considera-se trânsito a utilização das vias por pessoas, veículos e animais, isolados ou em grupos, conduzidos ou não, para fins de circulação, parada, estacionamento e operação de carga ou descarga".

Sendo possivel vislumbrar por trânsito tudo aquilo que se locomove de alguma forma, se movimenta, através de pessoas, animais e veículos, isolados ou em grupos. Então, podemos dizer que dependemos do trânsito para tudo, es- 
tando intimamente ligado às nossas necessidades básicas de sobrevivência, desde alimentação até saúde.

A origem do fenômeno trânsito é primitiva já que está ligado à atividade do ser humano de se locomover de um local para outro. Antigamente não havia necessidade de normas regulamentadoras diante do trânsito composto por pessoas e animais.

Com o desenvolvimento das civilizações e o avanço dos meios de transporte que ocorreu com a invenção da roda, foi surgindo à necessidade da implantação de normas para regulamentar a utilização das vias. (FRANZ; SEBERINO, 2012)

Com o aperfeiçoamento das rodas, novos veículos eram criados para atender as necessidades de locomoção e, concomitantemente antigos caminhos foram se transformando em estradas e construções de vias terrestres, facilitando o deslocamento. (FRANZ; SEBERINO, 2012)

Os problemas relacionados ao trânsito surgiram após a Revolução Industrial (1760-1830), com o advento da criação do motor e a fabricação de automóveis. Em 1897, o primeiro carro chegou ao Brasil, importado da França e pertencendo ao ativista José do Patrocínio. O proprietário certo dia emprestou o automóvel ao poeta Olavo Bilac, que provocou o primeiro acidente de trânsito no Brasil ao perder o controle do veículo e colidir com uma árvore. (FRANZ; SEBERINO, 2012)

Após o episódio, surgiu a preocupação em tornar o trânsito mais seguro. Com o objetivo de disciplinar o trânsito as Autoridades de São Paulo e Rio de Janeiro criaram em 1903 a concessão das primeiras licenças para dirigir, tornando obrigatório em 1906 a exigência do exame para habilitar motoristas. (FRANZ; SEBERINO, 2012)

Devido ao aumento acelerado de veículos circulando nas vias, dividindo o mesmo espaço com várias pessoas, se fez necessário introduzir regras na sociedade para organizar o fluxo. (FRANZ; SEBERINO, 2012) 
A primeira regra de trânsito introduzida na sociedade ocorreu treze anos após a chegada do primeiro carro no Brasil, em 27 de outubro de 1910, com o Decreto $n^{\circ} 8.324$, que tratou especificamente sobre os serviços de transporte por automóveis. (DEPARTAMENTO NACIONAL DE TRÂNSITO, 2010)

Em 28 de janeiro de 1941, foi instituído o primeiro Código de Trânsito Brasileiro através do Decreto Lei $n^{\circ}$ 2.994, que disciplinava a "circulação de veículos automotores de qualquer natureza, nas vias terrestres, abertas à circulação pública, em qualquer ponto do território nacional”. Contudo não obteve muito êxito em sua vigência, já que teve duração de 8 (oito) meses e logo foi revogado no mesmo ano pelo Decreto Lei $n^{\circ} 3.651$ de 25 de setembro de 1941, que deu nova redação ao Código Nacional de Trânsito criando o Conselho Nacional de Trânsito - CONTRAN subordinado ao Ministério da Justiça, e os Conselhos Regionais de Trânsito - CRT, com competência limitada aos respectivos governos estaduais. (FRANZ; SEBERINO, 2012)

Esse Código teve vigência por mais de 20 (vinte) anos e foi revogado em 1966. O Brasil vivia um momento de expansão econômica, marcado pela industrialização, ocorrendo um grande aumento da frota de veículos em circulação no país, sendo necessária uma revisão das leis, culminando com a aprovação da Lei $\mathrm{n}^{\circ} 5.108$, de 21 de setembro de 1966 . (HONORATO, 2009)

A nova lei produziu seus efeitos por 31 (trinta e um) anos, ou seja, até a aprovação do atual Código de Trânsito Brasileiro - CTB, Lei n 9.503, de 23 de setembro de 1997. (HONORATO, 2009)

O novo e atual Código de Trânsito entrou em vigor 120 (cento e vinte) dias após a sua publicação, sendo composto por leis, decretos e resoluções. Tem como escopo assegurar a segurança, eficiência, fluidez e a comodidade viária. (DEPARTAMENTO NACIONAL DE TRÂNSITO, 2010) 
Buscou adequar a legislação específica à nova realidade do Trânsito Brasileiro, incluindo a previsão de novas infrações e penalidades mais rigorosas, além do tratamento rígido aos condutores que dirigem alcoolizados. Inovou também, com um capítulo exclusivo para crimes de trânsito prevendo sanções penais às infrações cometidas no trânsito.

Em vigor há pouco mais de 18 anos, o CTB está na sua trigésima alteração, a última foi datada no dia 4 de maio de 2016, com a Lei $n^{\circ}$ 13.281. Essas alterações visam adequar as leis à realidade da sociedade que vem se transformando rapidamente no que se refere ao fenômeno trânsito.

Cumpre enfatizar alterações que versam sobre o tema deste trabalho, dirigir após ingerir bebida alcoólica ou após fazer uso de substâncias entorpecentes, que é sabidamente uma das principais causas de acidentes e mortes no trânsito brasileiro. Diante deste cenário, o legislador criou artigos específicos tipificando a conduta como infração administrativa.

A exordial lei $\mathrm{n}^{\circ}$ 9.503, de 23 de setembro de 1997, previa em seu artigo 165 a tolerância de influência de álcool de até seis decigramas por litro de sangue. Durante a vigência dessa lei o condutor poderia dependendo da quantidade de ingestão de bebida e do metabolismo do indivíduo, ingerir uma, duas ou até três cervejas ou taças de vinho, e só estaria impedido de assumir a direção se comprovado o nivel de álcool no sangue acima do tolerado. Partindo do princípio que a ingestão de pequenas doses de álcool não seria suficiente para alterar a capacidade psicomotora do condutor e refletir na condução do veículo pelo motorista. O condutor envolvido em acidente de trânsito ou alvo de fiscalização somente seria submetido a testes diante de evidentes suspeitas de ter excedido o limite de seis decigramas.

Ressalte-se que, "de 1998 a 2005, o número de mortes no trânsito cresceu $46,1 \%$, enquanto a população e a frota de veículos cresceram, respectivamente, a taxas de 16,8\% e 36\%". (PINSKY \& LARANJEIRA, 2010 apud SANTOS, 2015, p. 50) 
Diante da ineficácia da lei, adveio então a Lei $\mathrm{n}^{\circ} 11.275$, de 7 de fevereiro de 2006, que alterou a redação dos artigos 165 e 277. Aduziu que a conduta de dirigir sob influência de álcool ou de qualquer substância entorpecente que determine a dependência física ou psíquica será passivel de penalidade, no entanto o artigo foi omisso quanto à quantidade de álcool admitida no sangue.

Apesar desta última alteração no Código de Trânsito Brasileiro, dados da Organização Mundial da Saúde revelaram que era necessário uma atenção ao tema, no período de "2006 a 2009, o consumo abusivo de álcool seria responsável por $3,7 \%$ das mortes e $4,4 \%$ das doenças no mundo. Dentre as principais causas de morbimortalidade associada ao uso de álcool, destacam-se os episódios de violência e os acidentes de trânsito" (CENTRO DE INFORMAÇÕES SOBRE SAÚDE E ÁLCOOL, 2016, p.[1]).

Em estudo realizado pelo Centro de Informações sobre saúde e álcool (2016, p. [1]) mostra que "concentrações de álcool no sangue a partir de 0,3 g/1 (aproximadamente uma dose de bebida alcoólica) produzem diminuição da atenção, falsa percepção da velocidade, euforia e dificuldade de discernir espacialmente distintas luminosidades".

Foram esses indícios e a necessidade de uma lei mais rígida que deu causa a publicação da Lei $\mathrm{n}^{\circ} 11.705$, de 19 de junho de 2008, conhecida popularmente como lei seca. O grande impacto da Lei seca na sociedade foi o fato de estabelecer tolerância zero para condução de veículos automotores.

Assim, com o objetivo de analisar os últimos anos que antecederam a lei seca e o seu impacto, o Centro de Informações sobre saúde e álcool realizou a seguinte pesquisa:

Os dados referentes ao ano de 2008, para o conjunto das 27 cidades avaliadas, mostraram que, [...] 1,5\% dos indivíduos referiam ter dirigido, em pelo menos uma ocasião nos últimos 30 dias, após o consumo abusivo de álcool. Em 2007, estas frequências foram de 2,0\%, nos meses anteriores à implan- 
tação da lei seca, a frequência de beber e dirigir se manteve entre $1,8 \%$ e $2,2 \%$, diminuindo para $1,3 \%$ em julho de 2008 , mês seguinte à promulgação da nova lei. A menor frequência observada foi de $0,9 \%$ em agosto de 2008 , voltando a crescer em setembro e outubro, mas caindo novamente no início de 2009. Por fim, no mês de maio de 2009, a frequência registrada atingiu seu máximo em toda a série histórica, 2,8\% (CENTRO DE INFORMAÇÕES SOBRE SAÚDE E ÁLCOOL, 2016, p. [2]).

É possível concluir que após a implantação da lei houve uma maior conscientização das pessoas sobre o perigo da direção associada ao álcool, que logo se perdeu, e o antigo hábito foi ganhando espaço novamente. Sendo necessária mais uma vez a alteração na referida Lei.

Diante desse cenário, foi instituída a nova lei seca $n^{\circ}$ 12.760, de 20 de dezembro de 2012. Essa alteração no CTB além de aumentar a penalidade em relação à pecúnia, trouxe a novidade da penalidade de cassação no caso da reincidência da infração no período de 12 (doze) meses. Acompanhada da Resolução CONTRAN n 432 de 23 de janeiro de 2013, ampliou as possiblidades de meios de provas de verificar a influência de álcool ou de qualquer substância psicoativa.

Há controvérsia nessa lei quanto a legalidade do artigo 277, em aplicar as medidas administrativas e as penalidades previstas no artigo 165 ao condutor que se recusar a realizar o teste do etilômetro ou a qualquer outro procedimento com a finalidade de atestar a alcoolemia (art. 277, parágrafo $3^{\circ}$ ). Entende-se que o legislador não foi claro o suficiente quanto ao seu objetivo ao dispor o artigo.

Devido às dúvidas que pairavam sobre o tema, o Departamento Nacional de Trânsito - DENATRAN, em 4 de novembro de 2014 editou a portaria $n^{\circ} 217$, revogada pela portaria $n^{\circ}$ 219 , de 19 de novembro de 2014 que criou o enquadramento específico para o condutor que se recusar a se submeter a qualquer dos procedimentos previstos no art. 277 do CTB, sob o código de infração 757-9. 
Diante de um aparente conflito de normas, a Resolução CONTRAN $n^{\circ}$ 432/13 dispõe que só existe infração e consequente penalidade se comprovado o consumo de alguma substância psicoativa através dos meios de provas dispostos taxativamente. Em contrapartida, a Portaria do Denatran $n^{\circ}$ $219 / 14$, regulamenta uma penalidade e medida administrativa pela mera recusa aos procedimentos de provas, sendo ausente uma tipificação apropriada no capítulo de infrações do CTB. Dessa forma, a referida Portaria cria um código para uma conduta infracional que a rigor não existe, mas que deve ser aplicada pelo Sistema Nacional de Trânsito.

E por fim a última alteração, para sanar tais conflitos jurídicos a novel lei $n^{\circ} 13.281$ de 4 de maio de 2016, que entrou em vigor em novembro de 2016, incluiu o tipo infracional no artigo 165-A ao condutor que se "recusar a ser submetido a teste, exame clínico, perícia ou outro procedimento que permita certificar influência de álcool ou outra substância psicoativa, na forma estabelecida pelo art. 277", ou seja, criou artigo específico disposto no capítulo de Infrações.

O legislador na Resolução CONTRAN n 432/13 e no artigo 277 do CTB, disciplinou formas e procedimentos para certificar a influência de álcool ou outra substância psicoativa, e a partir do resultado dessas verificações, haverá a instauração do processo administrativo e consequente penalidade.

Destarte, é possivel a produção de qualquer prova admitida em direito. Nesse trabalho será tratado com mais ênfase, o teste do etilômetro e sua recusa, e a constatação por meio de sinais de alteração da capacidade motora, por serem provas corriqueiras no ato da fiscalização.

Salvo na hipótese de acidente de trânsito que possivelmente o condutor será encaminhado para um pronto-socorro, ou casos específicos em que realiza exame de sangue e/ou laboratoriais, preferencialmente o indivíduo alvo de fiscalização deve colaborar com o agente através dos meios capazes de produzirem provas no ato da abordagem. 
O Etilômetro, conhecido popularmente como bafômetro, é um equipamento utilizado para aferir a concentração de álcool etílico na corrente sanguínea de uma pessoa mediante a análise do ar pulmonar profundo.

Para que o aparelho seja utilizado, deve ter seu modelo aprovado pelo INMETRO e em verificação inicial e eventual. Anualmente deve ser feito uma verificação, e a sua data de vencimento deve estar indicada no último certificado. Para que o equipamento possa ser utilizado nas fiscalizações deve estar com suas verificações vigentes e ostentar selo de aprovado pelo INMETRO. (Portaria do INMETRO $n^{\circ}$ 006/02)

É comum os cidadãos confundirem verificação anual com a calibragem do equipamento, mas cumpre destacar que são procedimentos diversos. A calibragem é um procedimento de ajuste do aparelho, o qual as legislações são omissas quanto à periodicidade. A última consideração referente ao equipamento é para referenciar a legislação metrológica supracitada, que exige os descontos dos erros máximos admissíveis. Do resultado do etilômetro deverá ser descontada a margem de tolerância que será o erro máximo admissível, que equivale a: resultado de até $0,4 \mathrm{mg}$ desconto de 0,032 ; de $0,4 \mathrm{mg}$ a 2,0 $\mathrm{mg}$, desconto de $8 \%$; e, acima de 2,0 $\mathrm{mg}, 30 \%$.

Neste sentido, o condutor que realiza o teste do etilômetro, e é verificada a ingestão de bebida alcoólica, deverá constar no auto de fiscalização, conhecido também como auto de infração, a medição realizada pelo etilômetro (MR), e o valor considerado para autuação (VC), valor esse obtido após o desconto da margem de erro que o aparelho está sujeito. Exemplo: Se valor obtido da medição realizada é de 0,05 $\mathrm{mg} / 1$, o valor considerado para fim de infração e processo administrativo será de $0,01 \mathrm{mg} / 1$.

Esse desconto não significa que o condutor possa ingerir uma pequena quantidade de álcool, ou até mesmo que há uma tolerância propriamente dita para a quantidade de álcool no organismo do condutor. 
Cumpre diferenciar nesse momento o condutor alcoolizado e o condutor embriagado. É considerado condutor alcoolizado, aquele que ingere qualquer quantidade de álcool. Este responderá apenas na esfera administrativa. Além da esfera administrativa o condutor embriagado, responderá também pelo crime de trânsito previsto no artigo 306 do CTB, desde que tenha sido constatada a concentração de álcool superior a seis decigramas de álcool por litro de sangue ou três décimos de miligrama de álcool por litro de ar expelido pelos pulmões, ou através de sinais que indiquem essa alteração da capacidade psicomotora. Os condutores embriagados serão punidos com detenção de 6 (seis) meses a 3 (três) anos, multa e suspensão ou proibição de se obter a permissão ou a habilitação para dirigir veículo automotor. A Lei $\mathrm{n}^{\circ} 13.281 / 16$ trouxe ainda uma novidade com relação aos crimes de trânsito, criando o artigo 312-A, dispondo que se o juiz aplicar a substituição da detenção por pena restritiva de direito, o motorista deverá prestar serviços relacionados ao atendimento as vítimas de acidentes de trânsito.

Em um levantamento de dados feito pela equipe Operação Direção Segura - ODS, por amostragem no Estado de São Paulo e na Capital, é possivel verificar o número de condutores que realizaram o teste do etilômetro e desses, os que foram autuados.

A partir dessa tabela é possivel visualizar que é crescente ao longo dos anos o índice de condutores autuados, sendo que na Capital até setembro de 2016, 15\% dos condutores que realizaram o teste foram autuados. 
Tabela 1. Percentual de condutores autuados.

\begin{tabular}{|c|c|c|c|c|c|c|c|c|}
\hline \multicolumn{2}{|c|}{ Estado } & \multicolumn{3}{c|}{ Capital } \\
\hline \multirow{2}{*}{ ANO } & Operações & $\begin{array}{c}\text { Teste } \\
\text { etilôm. }\end{array}$ & Autuações & $\begin{array}{c}\% \\
\text { Autuações / } \\
\text { Testes }\end{array}$ & Operações & $\begin{array}{c}\text { Teste } \\
\text { etilôm. }\end{array}$ & Autuações & $\begin{array}{c}\% \\
\text { Autuações } / \\
\text { Testes }\end{array}$ \\
\hline 2013 & 68 & 12.746 & 1.226 & $9,6 \%$ & 29 & 6.032 & 617 & $10,2 \%$ \\
\hline $2014^{*}$ & 122 & 18.054 & 1.821 & $10,1 \%$ & 24 & 4.287 & 584 & $13,6 \%$ \\
\hline 2015 & 222 & 35.476 & 3.624 & $10,2 \%$ & 36 & 8.652 & 1.280 & $14,8 \%$ \\
\hline $2016\left(1^{\circ}\right.$ sem) & 128 & 22.022 & 2.581 & $11,7 \%$ & 23 & 7.935 & 1.267 & $16,0 \%$ \\
\hline 2016 (até 22/9) & 189 & 33.459 & 3.650 & $10,9 \%$ & 32 & 11.380 & 1.740 & $15,3 \%$ \\
\hline
\end{tabular}

${ }^{*}$ a partir de setembro de 2014, a ODSI passou a atuar com 7 equipes espal hadas pelo estado.

Fonte: (Operação Direção Segura, 2016).

Números que causam preocupação já que com as alterações das leis e a intensificação da fiscalização, se espera reação inversa.

Com todo o estudo realizado em cima deste meio de prova, conclui-se que esse ainda é o método mais preciso e utilizado pelos agentes fiscalizadores. Por garantir segurança no resultado e celeridade no procedimento de fiscalização.

A Resolução CONTRAN n ${ }^{\circ} 432 / 13$, regulamentou que além do teste do etilômetro e do exame clínico com laudo conclusivo realizado e firmado por médico perito, a alteração da capacidade motora pode ser constatada objetivamente pelo próprio agente de trânsito através de sinais de alteração.

Esse procedimento é considerado válido quando verificado e preenchido corretamente no auto de infração um conjunto de sinais de alteração da capacidade psicomotora, e não apenas um sinal.

São exemplos de sinais de alteração observados pelo agente fiscalizador: Sonolência; Olhos vermelhos; Vômito; Soluços; Desordem nas vestes; Odor de álcool no hálito; Agressividade; Arrogância; Exaltação; Ironia; Falante; Dispersão; Se o condutor i. sabe onde está; Sabe a data e a hora; Sabe seu endereço; Lembra dos atos cometidos; Se apresenta dificuldade no equilíbrio ou fala alterada (Resolução CONTRAN no 432/13). 
Por fim, o agente deverá afirmar expressamente se o condutor está sob influência de álcool ou de substância psicoativa.

Esse meio de prova é admitido pelo fato do agente de trânsito ser servidor público, regido pela Lei $n^{\circ} 8.027 / 90$, tendo que cumprir um rol taxativo de deveres previstos em sua função. Dentre os quais se destacam: I - manter conduta compativel com a moralidade pública; II - representar contra ilegalidade, omissão ou abuso de poder.

Além disso, os atos ou declarações dos agentes tem "presunção relativa de veracidade", pois são dotados de fé pública, ou seja, são tidos como verdadeiros. Presumindo que os sinais de alteração da capacidade psicomotora preenchidos no auto de infração pelo agente são verdadeiros.

Diante de todo o exposto, o condutor que for autuado a partir da verificação de sinais de alteração e tiver o auto de infração devidamente preenchido, dificilmente conseguirá reverter o processo administrativo, já que a constatação de mais de um sinal pelo agente é suficiente para caracterizar a penalidade em questão.

Em relação a recusa ao teste do etilômetro, trata-se do procedimento, no qual durante uma fiscalização é solicitado que o condutor faça o teste do etilômetro e esse se recusa. Em pesquisa divulgada pela Folha de S. Paulo, o número de motoristas que se recusam a fazer o teste do etilômetro aumentou 36\% entre janeiro de 2016 comparado com igual período de 2015. "Em 2015, 55,5 mil motoristas foram parados, e $3.483(6,9 \%)$ se recusaram a fazer o teste. No mesmo período de 2016, o número de condutores parados em blitz mais que dobrou, chegando 112 mil. Desses, 10,5 mil (9,45\%) decidiram não soprar o bafômetro" (FOLHA DE S. PAULO, 2016, p. [2]).

A recusa ao teste do etilômetro é recorrente por desconhecimento dos cidadãos das sanções aplicadas, que são semelhantes às cabíveis ao infrator que comprovadamente 
estiver dirigindo veículo sob influência de álcool, quais sejam: multa (dez vezes) e suspensão do direito de dirigir por 12 (doze) meses.

Nas defesas de processos administrativos é comum encontrar alegações no sentido de que o condutor não é obrigado a realizar o teste e a recusa não é suficiente para implicações, conforme transcrições abaixo:

A autoridade suspeitou e posteriormente requereu que eu fizesse o teste de bafômetro, contudo me recusei a fazer em razão de não estar sob efeito de álcool. No entanto a simples suspeita da autoridade de trânsito não lhe daria o direito de aplicar a multa, porque não se pode concluir que eu apresentava estado de embriaguez sem qualquer meio de comprovação (SISTEMA NACIONAL DE TRÂNSITO, JARI, 2016) ${ }^{1}$.

Muito se discute sobre a legalidade e constitucionalidade de uma infração gerada pela mera recusa do condutor em realizar o teste do etilômetro. A intenção do legislador ao inserir o parágrafo $3^{\circ}$ do artigo 277 no capítulo das medidas administrativas, era tentar coibir que motoristas alcoolizados saíssem impunes de uma fiscalização.

Vale analisar tal forma ensejadora de processo administrativo sob dois aspectos, o primeiro considerando o princípio constitucional "Nemo tenetur se detegere", e o segundo verificando a legalidade de um processo administrativo instaurado com base em enquadramento de uma infração omissa no CTB até a publicação da Lei $\mathrm{n}^{\circ} 13.281 / 16$.

Sobre o assunto é possivel visualizar duas correntes. A corrente minoritária, que entende ser uma faculdade do condutor se submeter ao teste do etilômetro. A realização compulsória fere o princípio constitucional a não incriminação. Além disso, o artigo 277 está previsto no capítulo de

${ }_{1}$ Recurso analisado e processo indeferido pela Junta Administrativa de Recursos de Infrações em 30 de setembro de 2016. 
medidas administrativas, não tendo natureza de infração, podendo ser abusiva ao princípio da legalidade, aplicar uma sanção sem cominação legal.

Em sentido contrário, é majoritária a corrente que a "multa pela recusa" não fere garantia constitucional, já que a Constituição Federal não dispõe expressamente que "ninguém é obrigado a produzir prova contra si mesmo". Esse suposto direito é fruto do princípio da não autoincriminação e da presunção de inocência convalidado pelo Pacto de São José da Costa Rica, redigido a fim de impedir a confissão mediante tortura, o que não se aplica ao caso em discussão.

Para regularizar essa questão que pairava posicionamentos extremos há anos, durante o desenvolvimento desse trabalho, o legislador criou a infração da recusa aos exames inserida no artigo 165-A do CTB no capítulo das infrações (Lei $\mathrm{n}^{\circ}$ 13.281/16, em vigor a partir de 1 de novembro de 2016).

O processo administrativo de alcoolemia no trânsito está previsto no CTB, do artigo 280 ao 290. Cumpre mencionar que o processo administrativo se divide em duas fases. A primeira é a fase do ato da fiscalização, na qual o agente de trânsito tipifica a infração, lavra o respectivo auto e cientifica o condutor. Na segunda fase, a autoridade de trânsito responsável, frente a legalidade do auto de infração e respeitando a ampla defesa e o contraditório, aplicará a penalidade.

Antes de aplicar a penalidade de multa, a autoridade vai verificar se o auto de infração preenche todos os requisitos formais necessários, se assim for, o infrator será notificado para caso queira, apresentar defesa da autuação nos padrões da Resolução CONTRAN no 299/08.

Finda a fase recursal da multa, os infratores dos artigos 165 e 165-A, pagarão a multa no valor de $R \$$ 2.934,70 (dois mil novecentos e trinta e quatro reais e setenta centavos) - 10 (dez) vezes o valor de uma multa gravíssima -, e em caso de reincidência no prazo de 12 (doze) meses o valor em dobro, o que equivale a $R \$ 5.869,40$ (cinco mil oitocentos e sessenta e nove reais e quarenta centavos). 
Esgotados todos os meios de defesa da infração na esfera administrativa, os pontos serão considerados para fins de instauração de processo administrativo para aplicação da penalidade de suspensão do direito de dirigir.

$\mathrm{O}$ processo administrativo é regulamentado pelo CONTRAN na Resolução $n^{\circ} 182 / 05$. Será instaurado o processo de suspensão sempre que o infrator atingir a contagem de vinte pontos, no período de 12 (doze) meses ou ter uma infração autossuspensiva, como é o caso dos artigos 165 e 165-A.

Da instauração do processo administrativo o condutor será cientificado, por meio de notificação na qual deverá constar o prazo para apresentação de defesa não inferior a 15 (quinze) dias, conforme artigo 10, da supracitada Resolução.

Após a análise da defesa, a autoridade proferirá decisão motivada e fundamentada. Caso a defesa seja acolhida, o processo será arquivado. Em caso de defesa que reste indeferida, o condutor será notificado da decisão, bem como da penalidade e da possibilidade de exercer seu direito de recurso.

A primeira instância recursal é composta pela Junta Administrativa de Recursos de Infrações - JARI, órgão autônomo e colegiado responsável pelo julgamento dos recursos interpostos contra a decisão da autoridade de trânsito. Seguido pela segunda instância formada pelo Conselho Estadual de Trânsito - CETRAN, órgão máximo do trânsito no Estado, responsável por julgar recursos em último grau na esfera administrativa.

Findas as fases recusais e transitada em julgado à decisão do processo administrativo, será aplicada a penalidade de suspensão do direito de dirigir por 12 (doze) meses, a qual é taxativa e vinculada, isto é, sem espaço de dosimetria para os julgados, conforme artigo 165 e 165-A do CTB.

No caso de reincidência da infração do art. 165 no período de 12 (doze) meses, a penalidade é de cassação por 2 (dois) anos do documento de habilitação. Observe-se que, na reincidência de "recusa aos exames", antes da novel lei, eram 
aplicadas as mesmas penalidades administrativas do artigo 165 e, assim, entendia-se pela aplicação também da cassação por 2 (dois) anos do documento de habilitação. Com a criação de um dispositivo específico, o art.165-A, o legislador, no parágrafo único, foi taxativo ao dispor que se aplica em dobro a multa prevista no caso de reincidência no período de até 12 (doze) meses, mas nada falou sobre cassação da $\mathrm{CNH}$, tampouco incluiu o artigo 165-A no rol de infrações do artigo 263, inciso II do CTB: "A cassação, então, do documento de habilitação dar-se-á, no caso de reincidência, no prazo de doze meses, apenas em relação às infrações previstas no inciso III do art. 162 e nos arts. 163, 164, 165, 173, 174 e 175".

Dessa forma, após a Lei $\mathrm{n}^{\circ} 13.281 / 16$, a reincidência no artigo 165-A no prazo de 12 (doze) meses, não enseja a penalidade de cassação do documento de habilitação, mas apenas a multa em dobro e nova suspensão pelo prazo de 12 (doze) meses.

Conforme dados do DETRAN-SP, em todo o Estado de São Paulo no ano de 2015 foram instaurados 49.000 (quarenta e nove mil) processos administrativos de suspensão de alcoolemia, já no ano de 2016 (até 31 de outubro), 53.792 (cinquenta e três mil setecentos e noventa e dois). O que demonstra um quadro crescente de fiscalizações e consequentemente do número de motoristas que podem ser punidos.

Dos 53.792 (cinquenta e três mil e setecentos e noventa e dois) processos instaurados de alcoolemia em 2016 até o final do mês de outubro, somente 15.392 (quinze mil e trezentos e noventa e dois) condutores apresentaram defesa, desses, $82.97 \%$ restaram indeferidos.

A partir desses dados é possivel vislumbrar o cenário crítico que nos encontramos. Mesmo com o enrijecimento das leis os números ainda são elevados.

O Governo do Estado de São Paulo por meio do Decreto $\mathrm{n}^{\circ} 58.881$, de 8 de fevereiro de 2013, considerando todas as legislações anteriormente mencionadas e a necessidade de 
urgência na redução de acidentes com vítimas, instituiu o Programa "Direção Segura" para a fiscalização de trânsito.

Trata-se de uma atividade do governo integrada entre as forças policiais do estado, sendo elas a policia civil, policia militar, policia técnico-científica e DETRAN-SP, objetivando a prevenção de acidentes de trânsito em âmbito Estadual em decorrência do uso de bebidas alcoólicas e substâncias psicoativas.

A fim de um programa mais efetivo e organizado, cada órgão participante possui seu papel definido. Em conversa com o coordenador Estadual da Operação, Antonio Carlos Lonel, em 12 de novembro de 2016, incube ao DETRAN, planejar, coordenar, supervisionar e realizar a gestão de dados dos resultados da operação; executar os testes de alcoolemia na modalidade "passivo", também denominada pré-teste, com o objetivo de identificar condutores de veículos que possivelmente tenham ingerido bebida alcoólica, em seguida encaminhar à Polícia Militar os condutores que se recusam a realizar o teste do bafômetro na modalidade "passiva" ou os que forem surpreendidos com níveis acima de zero, a fim de que a Polícia Militar realize os testes na modalidade "ativo" e elaborem os autos de infração. Além disso, desenvolve campanhas educativas como a distribuição de material de divulgação da Operação junto aos condutores que são liberados pelo motivo de indicarem índice zero no pré-teste do bafômetro.

Destaca-se que além da Operação Direção Segura composta por sete equipes formadas por funcionários voluntários do DETRAN em todo o Estado, sendo que no mesmo dia realizam duas operações de 2 (duas) horas e meia com 1 (uma) hora de intervalo em dois endereços distintos, a Polícia Militar realiza blitz diariamente para combater os condutores que dirigem após ingerirem bebida alcoólica.

Conforme relato do coordenador da ODS, atualmente em cada operação são abordados aproximadamente 160 (cento e sessenta) motoristas, desses, $10 \%$ geram infração. 
Em estudo realizado pelo Observatório Paulista de Trânsito verificou-se que em diversos anos, quando aumentou o número de autuações, reduziram-se as mortes por acidentes de transportes terrestres, e quando caíram as autuações, subiram as mortes por esses acidentes, ratificando a importância das fiscalizações.

Neste cenário, cumpre mencionar os membros do Sistema Nacional de Trânsito. As Juntas Administrativas de Recursos de Infrações - JARI, prevista no art. $7^{\circ}$, inciso VII, do CTB, é a primeira instância, responsável pelo julgamento dos processos administrativos de multas e processos de suspensão do direito de dirigir e cassação do documento de habilitação.

Importante ressaltar que cada órgão executivo de trânsito ou rodoviário tem as suas próprias JARIs. Assim cada órgão, seja ele municipal, estadual ou federal possui sua junta para julgar os recursos de infrações por eles aplicadas. No caso do DETRAN, as JARIs julgam tanto os recursos das multas de trânsito aplicadas pelo órgão, como também os julgamentos dos processos de suspensão do direito de dirigir e cassação da habilitação. Por exemplo, se a infração de multa foi aplicada pelo órgão de trânsito da Prefeitura, o recurso da multa deve ser interposto a JARI municipal.

Frise-se que suas competências estão descritas no artigo 17 do CTB e que cada JARI tem seu próprio regime, e conta com ajuda administrativa e financeira do órgão que faz parte.

Os recursos interpostos para as Juntas Administrativas de Recursos de Infrações que forem julgados indeferidos, podem ser recorridos no prazo de 30 (trinta) dias para o Conselho Estadual de Trânsito - CETRAN, a segunda instância do processo administrativo.

Em caso de deferimento do processo pela JARI, a autoridade de trânsito discordando poderá recorrer dessa decisão ao CETRAN, dispõe o artigo 288 do CTB.

$\mathrm{Na}$ linha do presente trabalho o Departamento Estadual de Trânsito do Estado de São Paulo - DETRAN-SP, teve uma 
iniciativa pioneira no país, criando Juntas Administrativas de Recursos de Infrações - JARIs Alcoolemia, específicas para os julgamentos exclusivos dos recursos dos processos de multas e suspensão dos motoristas que dirigem sob efeito de álcool ou outras substâncias psicoativas ou ainda que se recusam a realizar o teste do bafômetro. Antes eram julgados com os outros casos por todas as JARIs do departamento.

O DETRAN-SP considerando a gravidade e importância dos casos de motoristas que dirigem após ingerirem bebidas alcoólicas já criou 3 (três) JARIs de Alcoolemia, que são compostas por 6 (seis) membros. A primeira foi criada em novembro de 2015, a segunda em março de 2016 e a terceira junta em junho de 2016.

Com isso teve a centralização dos julgamentos, trazendo benefícios, como a melhora na qualidade dos julgamentos, além da celeridade para punir efetivamente aquele condutor que coloca em risco a segurança no trânsito.

Conforme dados obtidos com a coordenação da JARI, desde a centralização foram julgados 13.467 (treze mil e quatrocentos e sessenta e sete) processos, o que equivale a 1.122 (um mil e cento e vinte e dois) processos julgados por mês, antes da centralização os julgamentos eram feitos por todas as JARIs do departamento (37), em aproximadamente 380 (trezentos e oitenta) análises por mês.

Com a iniciativa é possivel visualizar que em um ano, praticamente triplicou o número de casos analisados, além disso, a avaliação ficou mais rigorosa, antes até $50 \%$ dos recursos eram acatados, hoje apenas 2,5\% dos recursos são deferidos.

Não é apenas no Brasil que beber e dirigir sujeita o condutor a penalidades administrativas e criminais, esse tema é de relevância mundial devido ao impacto que o ato pode causar à sociedade.

Em pesquisa realizada em 2012 pela Organização Mundial da Saúde - OMS, demonstrou que cerca de 3,3 milhões 
de mortes, ou 5,9\% de todas as mortes globais, foram atribuídas ao consumo de álcool. (CONSUMO..., 2014, p. [1])

Diante de dados mundiais, cada país tem sua própria legislação específica para regulamentar os procedimentos e sanções ao condutor que dirigir após ingerir bebida alcoólica. Dentre as diferenças nas legislações, o limite legal máximo de álcool permitido por cada país varia entre tolerância zero a $0,10 \%$ de álcool no sangue.

Apesar de o Brasil fazer parte da minoria dos países no qual a tolerância é zero, vamos verificar adiante que mesmo os que permitem uma pequena quantidade de álcool no sangue possuem uma legislação severa, prevendo até 60 (sessenta) dias de prisão ao condutor que se recusar a realizar o teste.

Cumpre mencionar que o meio de prova mais utilizado no Brasil, o teste do etilômetro, também é o mais aplicado em todo o mundo para verificar se o condutor ingeriu bebida alcoólica, seguido pelo exame de sangue (LEYTON; PONCE; ANDREUCCETTI, 2016, p. [168]).

Para aprofundar e melhor compreender o tema será discorrido a legislação de trânsito e os procedimentos de alguns países.

Nos Estados Unidos, cada Estado tem sua própria legislação quanto a fiscalização, processo administrativo e penalidades. Porém todos determinaram que a concentração de álcool no sangue, igual ou superior a 0,08\% é considerada crime. Esse limite é menor para os motoristas que exercem atividade remunerada $(0,04 \%)$ e praticamente inexistente para os motoristas com menos de 21 (vinte e um) anos variando de 0,02\% até tolerância zero dependendo do Estado (GOVERNORS HIGHWAY SAFETY ASSOCIATION, 2016, p. [1]).

Durante os procedimentos de fiscalização podem ser utilizados como meios de provas, o teste do etilômetro, exame de sangue e exame de urina, sendo que a recusa aos exames 
podem causar consequências em alguns Estados (HANNIBAL, 2016, p. [2]).

Todos os Estados possuem alguma determinação para bloqueio de ignição, na qual todos ou alguns motoristas infratores devem instalar em seu carro, e o motor do veículo somente será ativado após a realização do teste e não constatação de álcool pelo motorista (GOVERNORS HIGHWAY SAFETY ASSOCIATION, 2016, p. [1]).

Essa tecnologia que jamais foi desenvolvida no Brasil é muito interessante para coibir a reincidência desses condutores.

Além de diferenciar-se da legislação brasileira, é possível verificar peculiaridades em cada Estado. No Estado de Michigan o condutor que for pego pela primeira vez dirigindo com $0,08 \%$ de álcool no sangue, além das penalidades administrativas de suspensão e a penalidade pecuniária, poderá cumprir até 93 (noventa e três) dias de prisão. No caso da primeira reincidência no prazo de 7 (sete) anos, poderá prestar serviços comunitários. Destaca-se também, que a recusa ao teste do etilômetro pode ocasionar a suspenção do direito de dirigir por até 3 (três) anos.

Já no Estado da Flórida, as penalidades pecuniárias são mais altas e a suspensão da licença do condutor que é flagrado sob a influência de álcool pode chegar até 10 (dez) anos. Àquele que se recusa ao exame poderá ter sua licença suspensa por até 18 (dezoito) meses.

No Estado do Alaska a legislação é mais rigorosa em comparação aos demais Estados. O condutor que se recusar a realizar o teste do etilômetro pela primeira vez será penalizado com 3 (três) dias de prisão, deverá instalar o dispositivo de ignição no veículo, além de multa pecuniária no valor de $\$ 1.500$ (um mil e quinhentos) dólares, o que equivale a aproximadamente $\mathrm{R} \$ 5.000$ (cinco mil) reais.

Sendo que, se esse condutor cometer essa infração pela terceira vez no prazo de 15 (quinze) anos, será penalizado com 
60 (sessenta) dias de prisão e multa de $\$ 4.000$ (quatro mil) dólares. Vale lembrar que a nossa legislação atual prevê para o caso de reincidência dessa infração no período de 12 (doze) meses, apenas a penalidade do valor da multa em dobro.

Diante do exposto, é possivel verificar que apesar dos Estados Unidos admitirem uma tolerância de álcool no sangue para aquele motorista que dirigir após ingerir bebida alcoólica, os Estados possuem legislações mais severas comparadas ao Brasil, o que impacta diretamente na segurança viária e na sociedade em geral.

O Japão é muito severo nas questões de segurança no trânsito. Esta entre os países mais rígidos em relação às punições daqueles motoristas que dirigem após ingerirem bebidas alcoólicas.

Para o condutor que for flagrado conduzindo o seu veículo embriagado, (a embriaguez caracteriza-se pela incapacidade física de conduzir veículo automotor devido à influência de álcool, independentemente de sua concentração) poderá cumprir até 5 (cinco) anos de prisão em caso de reincidência ou multa até 1 (um) milhão de ienes. (RIGOR..., 2012, p. [2])

O condutor com a concentração de álcool no sangue igual ou superior a $0,3 \mathrm{mg} / 1$, ou por litro de ar igual ou superior a 0,15 miligramas, é considerado alcoolizado e será penalizado com até 3 (três) anos de reclusão ou multa até 500 (quinhentos) mil ienes. (JAPANESE LAW TRASLATION, 2016)

Conforme a supracitada legislação, na esfera administrativa o condutor com teor de álcool de $0,15 \mathrm{mg} / 1$ ar até inferior a $0,25 \mathrm{mg} / 1$ ar será penalizado com 13 (treze) pontos em sua licença para dirigir e a suspensão da carteira de motorista por 90 (noventa) dias. E o motorista com teor de álcool igual ou superior a $0,25 \mathrm{mg} / 1$ ar terá 25 (vinte e cinco) pontos na habilitação e seu cancelamento por 2 (dois) anos. O infrator com a somatória de 35 (trinta e cinco) pontos, terá a carteira cancelada por 3 (três) anos. 
Já no caso do motorista que se recusar a realizar os procedimentos na fiscalização estará sujeito a pena de reclusão de até 3 (três) meses ou multa no valor até 500 (quinhentos) mil ienes. (JAPANESE LAW TRASLATION, 2016)

O país mostra-se ainda mais sério, quando o condutor coloca em risco a segurança da coletividade. Outra regra importante no Japão referente ao trânsito é para o cidadão que tiver conhecimento, e deixar o condutor alcoolizado dirigir ou estiver dentro do veículo, tendo as mesmas implicações daquele infrator. (RIGOR..., 2012, p. [2])

Cumpre frisar que no Japão até mesmo os donos de estabelecimento que vendem bebidas são responsáveis pela segurança no trânsito. Sendo obrigado a chamar um táxi se tiver um cidadão alcoolizado no seu bar/restaurante, ou paga uma multa. Existem empresas especializadas para levar com segurança o motorista alcoolizado para a sua residência.

Conforme informações no site oficial do Governo do Reino Unido, o condutor que conduzir um veículo automotor na Inglaterra após ingerir bebida alcoólica, poderá ser penalizado pelos Magistrados, que arbitram as sanções após ouvir o caso.

As penalidades podem variar conforme a gravidade da ofensa. O condutor poderá ser multado no valor de até £2.500 (dois mil e quinhentas) libras, ser proibido de dirigir e até mesmo ser preso por 3 (três) meses. (GOV UK, 2016)

Aduz ainda, que o motorista alcoolizado poderá ficar 12 (doze) meses ou mais proibido de dirigir. Nesses casos o infrator pode tentar reduzir a pena realizando um curso de reabilitação, porém a decisão da diminuição da pena cabe ao tribunal.

Assim como outros países, a Inglaterra prevê um limite de tolerância de álcool no sangue no valor de 0,08 mg por litro.

No caso do condutor que ingeriu bebida alcoólica conduzir, ou até mesmo a sua mera tentativa, terá penalidades severas, tais como: 6 (seis) meses de prisão, uma multa ilimitada a ser arbitrada e a suspensão da licença por pelo 
menos 1 (um) ano. Em caso de reincidência no prazo de 10 (dez) anos, a suspensão será de 3 (três) anos. (GOV UK, 2016) Destaca-se que a simples intenção do indivíduo de conduzir veículo após ingerir bebida alcoólica é suficiente para culminar em penalidades.

O condutor que se recusar a realizar os exames no ato da fiscalização (etilômetro, exame de sangue e urina), será penalizado igualmente ao condutor que se submete aos testes. Sendo condenado a 6 (seis) meses de prisão, uma multa de valor ilimitado e suspensão da licença por pelo menos 1 (um) ano.

O motorista alcoolizado que causar morte devido a condução descuidada poderá ser condenado a 14 (quatorze) anos de prisão, devendo pagar uma multa de valor ilimitado e ser proibido de dirigir por pelo menos 2 (dois) anos, além de ter que fazer um teste de condução prolongado antes de ter sua licença devolvida.

Além do exposto, se diagnosticado como infrator de alto risco, a sua habilitação não será devolvida automaticamente no final do cumprimento da penalidade. Sendo entregue apenas após exame médico. É considerado infrator de alto risco, aquele que foi condenado por 2 (duas) infrações de condução de álcool em 10 (dez) anos. A recusa aos exames também o caracteriza como infrator de alto risco.

Na Espanha no ato da fiscalização a verificação da ingestão de álcool normalmente é realizada através do etilômetro. A pedido do motorista ou por ordem judicial, poder-se-ão repetir os exames a efeitos de contraprova, que poderão consistir em exame de sangue, urina ou outros análogos.

Os agentes de trânsito poderão submeter aos exames mencionados: qualquer usuário da via; o condutor de veículo envolvido em acidente; aquele que conduzir com sintomas evidentes de alcoolemia; condutores que forem denunciados pelo cometimento de alguma irregularidade no trânsito; e aqueles que forem alvos de fiscalização. 
Conforme Regulamento Geral de Circulação da Espanha, o limite de tolerância permitido no sangue para ingestão de bebida alcoólica associada a direção não poderá ser superior a 0,5 gramas por litro.

Quando se tratar de motorista que exerce atividade remunerada, não poderá conduzir com uma taxa de álcool no sangue superior a 0,3 gramas por litro ou de álcool no ar expirado superior a 0,15 miligramas por litro.

A supracitada legislação aduz ainda, que para os permissionários foi estipulada a mesma tolerância aplicada aos condutores que exercem atividade remunerada, ou seja, não poderão superar a taxa de álcool no sangue de 0,3 gramas por litro, nem de álcool no ar expirado de 0,15 miligramas por litro durante o período de dois anos da obtenção da permissão ou licença que lhes habilita para conduzir.

Se o resultado do exame atingir um valor superior ao permitido, ou ainda sem alcançar esse limite, e a pessoa examinada apresentar sintomas evidentes de se encontrar sob a influência de bebidas alcoólicas, o agente submeterá o motorista para uma maior garantia e a efeito de contraprova, à realização de um segundo exame de detecção alcoólica pelo ar expirado, mediante um procedimento similar ao que serviu para efetuar o primeiro exame, do qual terá de lhe informar previamente. Sendo que da realização do primeiro para o segundo deve-se aguardar 10 (dez) minutos. Nesse momento o motorista poderá optar por realizar a contraprova por meio de exame de sangue, urina e análogos, sendo que deverá subsidiar o translado até o centro médico bem como os exames realizados.

Os condutores com taxas de álcool superiores as permitidas, ou aqueles que descumprirem a obrigação de se submeter aos exames para constatação da presença de álcool serão sancionados com multa no valor de $€ 1.000,00$ (um mil) euros, o que equivale a aproximadamente $\mathrm{R} \$ 3.480,00$ (três mil quatrocentos e oitenta) reais. Verificando que em relação 
à pecúnia a penalidade aplicada é bem próxima a legislação Brasileira.

Além disso, os condutores com taxa de álcool superior a regularmente estabelecida perdem pontos na habilitação. Os condutores comuns com mais de $0,50 \mathrm{mg} / 1$ de ar expirado, os profissionais e titulares de carteira de habilitação com menos de dois anos de permissão com mais de 0,3 mg/1 de ar expirado e os condutores que descumprem a obrigação de submeter-se aos exames de detecção de álcool perdem 6 (seis) pontos.

Os condutores comuns com taxa superior a 0,25 até 0,50 , os profissionais e os permissionários com taxa superior a 0,15 até 0,30 , perdem 4 (quatro) pontos.

Na esfera criminal, o condutor que se negar a se submeter aos exames legalmente estabelecidos para a comprovação das taxas de alcoolemia, será penalizado com as penas de reclusão de 6 (seis) meses a 1 (um) ano e privação do direito de conduzir veículos motorizados e ciclomotores por tempo superior a 1 (um) e até 4 (quatro) anos.

Diante do exposto, é possível notar que a pena pode ser mais severa àquele condutor que se recusa a colaborar com os procedimentos, pois consideram uma obrigação do condutor realizá-los. Ressalta-se também que na Legislação Espanhola os ciclistas estão sujeitos aos mesmos procedimentos e penalidades dos motoristas de veículos automotores.

Diante da importância e gravidade do assunto, a Faculdade de Medicina da Universidade de São Paulo (FMUSP), com apoio da FAPESP, realizou pesquisa acerca de mortes violentas, e concluiu que $40 \%$ das mortes no trânsito na capital têm relação com o uso de álcool.

Durante 19 (dezenove) meses - junho de 2014 a dezembro de 2015 - em diferentes dias da semana e diferentes turnos, foram reunidos dados de 656 (seiscentos e cinquenta e seis) vítimas, mas nem todas se encaixaram nos critérios estabelecidos e somente 365 (trezentos e sessenta e cinco) 
autópsias foram realizadas em unidades do Instituto Médico Legal - IML. Dos critérios utilizados para selecionar as vítimas, destaca-se: somente maiores de 18 (dezoito) anos, as autópsias realizadas até 12 (doze) horas após a ocorrência do ferimento fatal e não ter recebido tratamento médico por 6 (seis) horas ou mais antes de morrer.

Além de informações sobre o contexto da morte, também foram obtidas amostras de sangue das vítimas para avaliação da taxa de alcoolemia, em média a taxa era de 1,10 grama de álcool por litro de sangue, uma quantidade considerada alta, o equivalente à ingestão de aproximadamente cinco latas de cerveja para um homem com cerca de 70 kilos. (TOLEDO apud ANDREUCCETTI, 2016, p. [2]).

$\mathrm{O}$ estudo mostrou que dentre as mortes violentas causadas após consumo de álcool, 42,9\% são acidentes de trânsito.

Essa pesquisa mostra a realidade brasileira que precisa ser mudada. O Brasil hoje é o quarto país no mundo em acidentalidade no trânsito, sendo que a maior parte desses acidentes são causados pelo o uso de bebida alcoólica associada a direção veicular. (CARDOSO, 2016, p. [2])

Conclui-se, também, com a pesquisa, que o impacto desses números repercute em toda a sociedade, na medida em que são gastos milhões de reais em todo o Brasil em hospitais públicos para socorrer vítimas de acidentes de trânsito.

\section{CONCLUSÃO}

O presente trabalho objetivou o estudo da legalidade dos meios de prova no processo administrativo de alcoolemia, analisando todos os procedimentos englobados nesse processo, em consonância com os princípios constitucionais, bem como com as alterações ocorridas nas legislações relacionadas.

Como constatado com os estudos realizados, a lei brasileira determinou tolerância zero. Dentre os meios de provas existentes para tanto, os mais recorrentes são o teste do 
etilômetro e a comprovação por sinais de alteração da capacidade psicomotora.

Muito se discutia sobre a legalidade das implicações administrativas decorrente da mera recusa em se submeter à realização dos exames para verificação da ingestão de bebida alcoólica, sob o fundamento de ausência de amparo legal no capítulo "das infrações" do Código de Trânsito Brasileiro CTB, o que poderia violar princípios constitucionais.

Sem dúvida, considerando o risco que se impõe à sociedade quando motoristas alcoolizados dirigem, o direito coletivo deve ser sobreposto ao direito de não produzir provas contra si. Além disso, o dever do Estado em garantir a segurança viária possui primazia diante do individual.

Diante disto, para sanar, definitivamente, esse debate, adveio a lei $\mathrm{n}^{\circ} 13.281 / 16$, que incluiu o artigo 165-A no capítulo "das infrações" do CTB, dispondo sobre as penalidades e medidas administrativas cabiveis ao condutor que se recusar a realizar os procedimentos no ato da fiscalização.

Apesar dessa solução legislativa que amplia a punição sem a utilização de subterfúgios formais, observa-se que muitos condutores ainda acreditam que a ingestão de bebida alcoólica em pequena quantidade não é capaz de produzir alterações de comportamento suficientes para impedi-los de realizar uma condução segura. Isso pode ser facilmente constatado pelo fato de que, mesmo com o enrijecimento das leis, o número de infrações lavradas e processos administrativos instaurados são altíssimos.

Ressalta-se que o número de acidentes com vítimas de trânsito no Brasil ainda é considerável, mesmo com todas as mudanças citadas. São dados que impactam diretamente no desenvolvimento social e econômico do país, na medida em que é necessária a destinação de vultosos valores dos cofres públicos para atender essa causa tão relevante para todos.

Enfim, à guisa de conclusão, comparando com as leis de outros países, apesar das recorrentes alterações das legisla- 
ções com a intenção de deixá-las mais rigorosas, percebe-se que os diplomas brasileiros ainda são frágeis e necessitam de ajustes. Outros países que conseguiram resultado satisfatório no combate aos motoristas que desrespeitam as leis de trânsito (principalmente, no que diz respeito à ingestão de bebida alcoólica), possuem punições muito mais severas. Dessa forma, é necessário que tenhamos uma atenção especial para esse assunto tão importante, para que possamos punir efetivamente aqueles infratores, afastando-os do trânsito, e dando uma resposta para a toda a sociedade no que diz respeito à garantia de uma efetiva segurança no trânsito.

\section{REFERENNCIAS}

ARAUJO, Julyver Modesto. Código de Trânsito Brasileiro: Legislação de trânsito anotado e comentado. $6^{\mathrm{a}}$ ed. São Paulo: Letras Jurídicas, 2016.

BRASIL. Constituição da República Federativa do Brasil: promulgada em 5 de outubro de 1988 .

Decreto $\mathrm{n}^{\circ}$ 58.881, de 8 de fevereiro de 2013. Institui o Programa "Direção Segura" para a fiscalização de trânsito e dá providências correlatas.

. DEPARTAMENTO NACIONAL DE TRÂNSITO. Portaria n ${ }^{\circ} 219$, de 19 de novembro de 2014.

. Lei $n^{\circ}$ 9.503, 23 de setembro de 1997. Institui o Código Nacional de Trânsito.

Lei $\mathrm{n}^{\circ} 11.275$, de 7 de fevereiro de 2006. Altera a redação dos arts. 165, 277 e 302 da Lei $n^{\circ}$ 9.503, de 23 de setembro de 1997, que institui o Código de Trânsito Brasileiro.

Lei $\mathrm{n}^{\circ} 11.705 / 2008$, de 19 de junho de 2008. Altera a Lei $\mathrm{n}^{\circ}$ 9.503, de 23 de setembro de 1997, que 'institui o Código de Trânsito Brasileiro', e a Lei $\mathrm{n}^{\circ}$ 9.294, de 15 de julho de 1996, que dispõe sobre as restrições ao uso e à propaganda de produtos fumígeros, bebidas alcoólicas, medicamentos, terapias e defensivos agrícolas, nos termos do $\S 4^{\circ}$ do art. 220 da Constituição Federal, para inibir o consumo de bebida alcoólica por condutor de veículo automotor, e dá outras providências. 


\section{A LEGALIDADE DA PRODUÇÃO DE PROVAS DOS PROCESSOS \\ ADMINISTRATIVOS DE ALCOOLEMIA NO TRÂNSITO}

. Lei $\mathrm{n}^{\circ}$ 12.760, de 20 de dezembro de 2012. Altera a Lei $\mathrm{n}^{\circ}$ 9.503, de 23 de setembro de 1997, que institui o Código de Trânsito Brasileiro.

Lei $\mathrm{n}^{\circ}$ 13.281, de 4 de maio de 2016. Altera a Lei $\mathrm{n}^{\circ}$ 9.503, de 23 de setembro de 1997 (Código de Trânsito Brasileiro), e a Lei n ${ }^{\circ} 13.146$, de 6 de julho de 2015 .

MC. Departamento Nacional de Trânsito. Conselho Nacional de Trânsito. 100 anos de legislação de trânsito no Brasil. 1910-2010. Brasília: Ministério das Cidades, 2010.

. MINISTÉRIO DO DESENVOLVIMENTO, INDÚSTRIA E COMÉRCIO EXTERIOR INSTITUTO NACIONAL DE METROLOGIA, NORMALIZAÇÃO E QUALIDADE INDUSTRIAL - INMETRO INMETRO. Portaria n ${ }^{\circ} 006$ de 17 de janeiro de 2002. Disponivel em: < http://www.inmetro.gov.br/rtac/pdf/ RTAC000750.pdf >. Acesso em: 10 Out. 2016.

CARDOSO, Cintia. Brasil é o quarto país com mais mortes no trânsito na América, diz OMS. Folha de S. Paulo. 19/05/2016. Disponivel em:http:// www1.folha.uol.com.br/cotidiano/2016/05/1772858-brasil-e-o-quarto-pais-com-mais-mortes-no-transito-na-america-diz-oms.shtml. Acesso em: 10 Nov. 2016.

CARDOSO, William. Cresce número de motoristas que recusam a fazer bafômetro em SP. Folha de S. Paulo. 07/11/2016. Disponivel em: < http:// www 1.folha.uol.com.br/cotidiano/2016/11/1829990-cresce-numero-de-motoristas-que-se-recusam-a-fazer-bafometro-em-sp.shtml >. Acesso em: 07 Nov. 2016.

Resolução n ${ }^{\circ} 432$, de 23 de janeiro de 2013. Dispõe sobre os procedimentos a serem adotados pelas autoridades de trânsito e seus agentes na fiscalização do consumo de álcool ou de outra substância psicoativa que determine dependência, para aplicação do disposto nos arts. 165, 276, 277 e 306 da Lei $n^{\circ}$ 9.503, de 23 de setembro de 1997 - Código de Trânsito Brasileiro (CTB).

CENTRO DE INFORMAÇÕES SOBRE SAÚDE E ÁLCOOL. Direção de veículos motorizados após consumo abusivo de bebidas alcoólicas, Brasil, 2006 a 2009. 2016. Disponivel em: <http://www.cisa.org.br/artigo/447/direcao-veiculos-motorizados-apos-consumo-abusivo.php>. Acesso em: 21 Jul. 2016.

CONSUMO de álcool matou 3,3 milhões de pessoas em 2012, diz OMS. Globonews, 10 mai. 2014. Disponivel em: <http://g1.globo.com/bemestar/ noticia/2014/05/consumo-de-alcool-matou-33-milhoes-de-pessoas-em-2012-diz-oms.html>. Acesso em: 30 Out. 2016. 
FRANZ, Cristiane Maria; SEBERINO, José Roberto Vieira. A história do trânsito e sua evolução. 2012. 24 f. Monografia (Pós-Graduação Latu Sensu, em Gestão, Educação e Direito de Trânsito), Joinville, 2012.

GOVERnORS HIGHWAY SAFETY ASSOCIATION. Drunk Driving Laws, november 2016. Disponivel em: < http://www.ghsa.org/html/stateinfo/laws/ impaired_laws.html >. Acesso em: 29 Out. 2016.

GOV.UK. Drink-driving penalties. 2016. Disponivel em: <https://www.gov. uk/drink-driving-penalties >. Acesso em: 07 Nov. 2016.

HANNIBAL, Bestsy Simmons. DUI: Refusal to Take a Field Test, or Blood, Breath or Unire Test. S.d Disponivel em: < http://dui.drivinglaws.org/ resources/dui-refusal-blood-breath-urine-test.htm\# >. Acesso em: 30 Out. 2016.

HONORATO, Cássio Mattos. O Trânsito em Condições Seguras. Campinas; Ed. Millennium, 2009.

JAPANESE LAW TRANSLATION. Road Traffic Act. August 27, 2010. Disponivel em: <http://www.japaneselawtranslation.go.jp/law/detail/?re=02 $\& d n=1 \& x=0 \& y=0 \& c o=1 \& i a=03 \& y o=\& g n=\& s y=\& h t=\& n o=\& b u=\& \mathrm{ta}=\& \mathrm{ky}=\% \mathrm{E}$ 9\%81\%93\%E8\%B7\%AF\%E4\%BA\%A4\%E9\%80\%9A\%E6\%B3\%95\&page=8>. Acesso em: 20 Nov. 2016.

LEYTON, V; PONCE, J; ANDREUCCETTI, G. Problemas especificos: álcool e trânsito. 2016. Disponivel em: <http://www.cisa.org.br/UserFiles/File/ alcoolesuasconsequencias-pt-cap8.pdf>. Acesso em: 28 Out. 2016.

RIGOR de "lei seca japonesa" aumenta segurança no trânsito do país. Jornal Nacional. 03 Jul.2012. Disponivel em: < http://g1.globo.com/jornal-nacional/noticia/2012/07/rigor-de-lei-seca-japonesa-aumenta-seguranca-no-transito-do-pais.html>. Acesso em: 02 Nov. 2016.

SANTOS, Vanilda Aparecida dos. Álcool e direção: uma análise psicopolítica. Curitiba: Juruá, 2015.

TOLEDO, Karina. 40\% das mortes no trânsito na capital têm relação com o uso de álcool, aponta estudo. Agência FAPESP. 9 de novembro de 2016. Disponivel em: <http://agencia.fapesp.br/40_das_mortes_no_transito_na_capital_tem_relacao_com_o_uso_de_alcool/24275/>. Acesso em: 9 Nov. 2016.

WORLD HEALTH ORGANiZATION. Alcohol. Jan. 2015. Disponivel em: < http://www.who.int/mediacentre/factsheets/fs349/en/>. Acesso em: 28 Out. 2016. 